Diabetologia $9,387-390(1973)$

(C) by Springer-Verlag 1973

\title{
Carbohydrate Tolerance in the Very Aged
}

\author{
M. J. Smith and M. R.P. Hall \\ St. Luke's Hospital, Guildford and The Faculty of Medicine, University of Southampton \\ Received: August 18, 1972, and in revised form: May 5, 1973
}

Summary. Fifty-three elderly non-diabetic volunteers aged 85 to 96 years were studied when they had reached their pre-admission health state before their discharge from the acute assessment wards of a Geriatric Unit. Blood sugar levels and their corresponding plasma insulin levels were estimated after a $50 \mathrm{~g}$ glucose load. Thirtyfour patients had normal curves, thirteen had an abnormal 2h. Blood sugar over $120 \mathrm{mg} / 100 \mathrm{ml}$ and six (all women) had two or more abnormal levels. Carbohydrate intolerance was not related to age, obesity or a positive family history. The results were compared to two groups of young controls, viz nineteen healthy post partum women mean age $29.9 \mathrm{yrs}$, and twenty-one healthy women mean age 52 years, admitted for investigation of post menopausal bleeding. With increasing age, the peak levels of glucose and insulin are delayed and when carbohydrate intolerance develops the rate of insulin secre. tion remains the same. The glucose and insulin values closely follow each other and there is no suggestion that insulin secretion is reduced with age. In fact the elderly diabetic shows increased insulin secretion suggesting insulin antagonism or inactivity unrelated to obesity.

Key words: Carbohydrate tolerance plasma glucose levels plasma insulin levels, aged normals, diabetes antagonism
Carbohydrate tolerance declines with increasing age, thus hyperglycaemia becomes commoner in old age [1]. The evidence for this is based on the Bedford Diabetes Survey [2] and the United States Department of Health Statistics [3].

Very old people, however, have not been studied in any detail; ages supporting the claim for carbohydrate intolerance being given as over 60 years, $70+$ years and $70-79$ years. Only Joslin and his colleagues [4] seem to have considered the onset of diabetes in the ninth decade and then only to comment on its rarity. Korenchevsky [5] suggests that those who have lived to great age have aged, from the physiological point of view, more "normally" and are, therefore, less likely to have disturbance of endocrine or metabolic function. Further, while many people aged between 70 and 90 years have undoubted hyperglycaemia in response to two successive doses of glucose [6], Bogdanovich [7] has shown that some very old people do not get this hyperglycaemia and respond quite "normally" to the "double" glucose tolerance test. Chesrow and Blayer [8] included 25 subjects over 80 years in their Survey, but apart from confirming that the glucose tolerance curve is prolonged, they found no significant difference between the curves of subjects aged $60-69,70-79$ and $80-89$ years.

For these reasons we felt that the further study of a group of aged people (over 85 years) was justified, to attempt to discover whether or not carbohydrate tolerance had in fact declined in this group and whether the undoubted diminution of sugar tolerance which has been observed in groups of elderly people is truly a state of the aged as opposed to an age-linked condition

* Both formerly of the Department of Medicine, University of Neweastle upon Tyne. such as overt arterial disease which has also been shown to have an association with hyperglycaemia [9].

\section{Materials and Methods}

Since it was not possible to obtain a random sample of healthy elderly people, aged more than 85 yrs., who were living 'normally' in the community, the material studied consisted of a randomly selected sample of patients who had been admitted to the Geriatric Unit of the Newcastle General Hospital, and who, having recovered their former state of health, were about to be discharged. Selected subjects were asked if they would undergo an oral glucose tolerance test (G.T.T.) and the details of the test were explained to them. Two subjects refused and a total of 53 subjects (age range 85$96 \mathrm{yrs}$ ) out of a total of 106 were studied. All were given a $300 \mathrm{~g}$ carbohydrate diet for three days before the test and it proved necessary to give one-third to a half of this amount in liquid form as Hycal. A standard oral glucose tolerance test (G.T.T.) was performed, blood being taken fasting and at $30 \mathrm{~min}$ intervals for $150 \mathrm{~min}$. Blood sugar levels were estimated by the Ferricyanide method of Hoffman [10] and plasma insulin levels by the double antibody method, using Insulin I 125. [11].

The results obtained from the study of these patients are compared with two other groups - one consisting of 19 women, mean age 29.9 years, who had been delivered of a normal weight infant, within two years of the birth; the other consisted of 21 healthy women, mean age 52 years, admitted for investigation of postmenopausal bleeding. In the first group, the G.T.T. was performed as an out-patient without special preparation. In the second group, each patient was prepared with a $300 \mathrm{~g}$ carbohydrate diet and the G.T.T. performed on the third day before surgery. 
The criteria for a normal glucose response was a fasting blood glucose of less than $110 \mathrm{mg} / 100 \mathrm{ml}$, one hour of less than $180 \mathrm{mg} / 100 \mathrm{ml}$ and two hours of less than $120 \mathrm{mg} / 100 \mathrm{ml}$.

\section{Results}

\section{Comparison of Elderly Group to Younger Controls - Glucose and Insulin Values.}

The details of the three main groups are shown in Table 1 . The mean glucose/insulin values are given with the standard deviation and standard error.

The elderly have been divided into three groups as a result of their response to the oral G.T.T.: - Group A, thirty-four subjects, ten male and twenty-four female who had normal results; Group B, thirteen subjects, three male and ten female who had a two hour blood sugar in excess of $120 \mathrm{mg} / 100 \mathrm{ml}$, and Group C, six subjects, all women who had two or more abnormal glucose levels.

The table shows that each of these groups was comparable in respect of age, mean percentage ideal body weight and height. It is interesting that Group $\mathrm{C}$ was entirely female, of small stature and of relatively normal body weight. The overall female to male ratio in the whole group was 3:1 which was the same as in the local population over 85 years [12].

The youngest group shows a flat glucose curve with the peak glucose and insulin values at $30 \mathrm{~min}$; in the postmenopausal group, the peak glucose and insulin values are again at $30 \mathrm{~min}$, but both values remain higher than the younger controls at $60 \mathrm{~min}$ before falling to normal values at $120 \mathrm{~min}$. In the elderly Group $A$, the peak glucose value is at 60 min coinciding with the peak insulin and very close to the values of the postmenopausal women. The $120 \mathrm{~min}$ insulin values rise with each group from $27 \mu \mu \mathrm{g} . / \mathrm{ml}$ for the youngest patients to $34 \mu \mu \mathrm{g} / \mathrm{ml}$ for the postmenopausal women and to $45 \mu \mu \mathrm{g} / \mathrm{ml}$ for the elderly subjects (Group A). Thus, with increasing age, the normal glucose curve, which only varies in the time the glucose takes to reach peak, is maintained by slight, but definite, increase in insulin values at $60 \mathrm{~min}$ and $120 \mathrm{~min}$ with an insulin peak which matches the glucose peak. In fact, all three curves show close similarity between the glucose and insulin response.

In the elderly groups those with slight impairment of carbohydrate tolerance (Group B) have a delay in the peak insulin which is maximal at 90 min along with the glucose, while in Group C, which might be termed a diabetic group, the peak insulin response is delayed to $120 \mathrm{~min}$. Thus, the peak insulin response to the oral glucose stimulus occurs later in each group and suggests declining carbohydrate tolerance.

\section{Diagnostic Analysis of the Group of Aged Patients}

$\mathrm{It}$ is well recognised that diagnoses are often multiple in elderly patients, and it is possible that this could

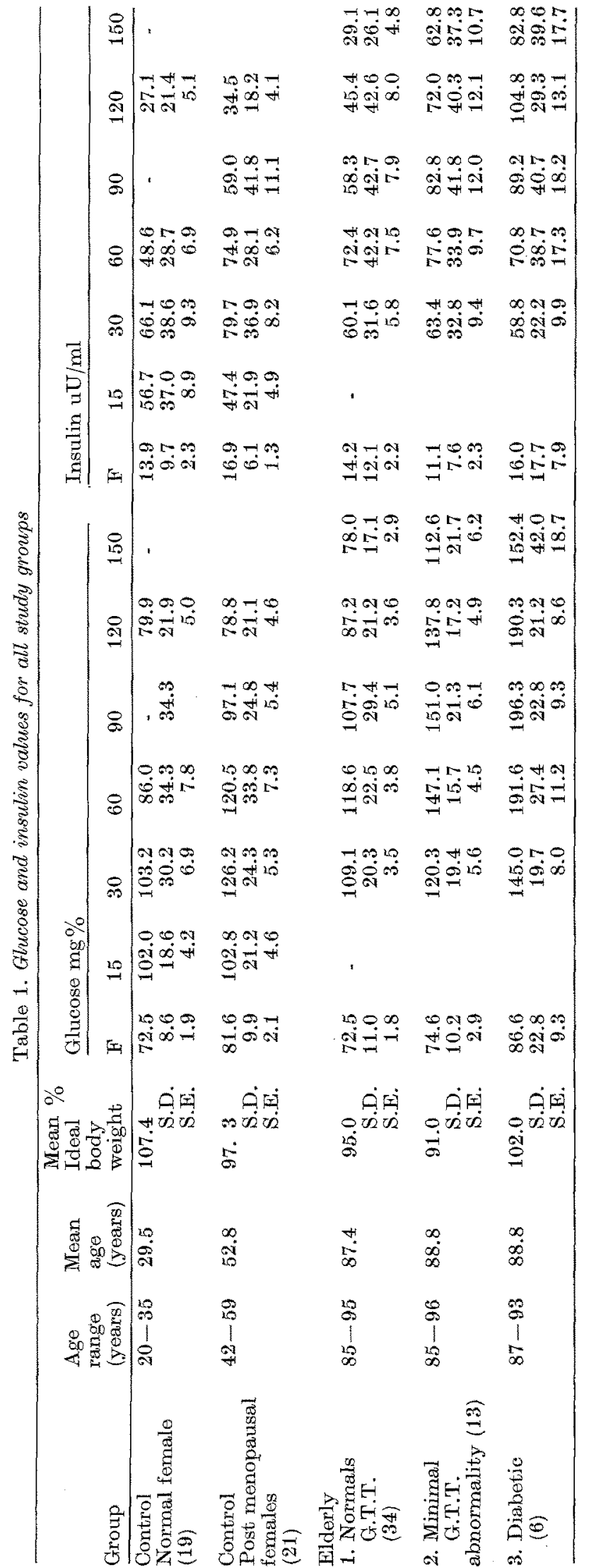


affect the results. However, only one patient (in the whole series) had a family history of diabetes and the distribution of pathology between the three groups of elderly was similar. In 15 patients the major pathology was skeletal, in 12 it was respiratory and in 14 it was vascular. In Group B half the subjects had possible explanations for their minimal abnormality. One patient had previously been on steroids for her rheumatoid arthritis and another had adrenal adenomata (a not uncommon finding in the elderly) at autopsy one year later; two men and one woman had raised blood ureas, a condition recognised to give rise to glucose intolerance [13]; two patients had mild 'organic brain syndrome', a condition in which the adrenal cortex is thought to be more re-active to stress [14].

\section{Discussion}

The reason why man loses his ability to respond "normally" to a glucose load with advancing age is still obscure, but on "a priori" reasons it would seem to be due to one or more of the following reasons:

1. Inability of islet cells to secrete enough insulin to deal with the sugar load.

2. Absorption of glucose from the gut may be delayed so that peak levels are reached more slowly and hence insulin levels correspond to the absorption rate. Alternatively the mechanism of islet stimulation may be defective.

3. The mechanism of insulin secretion remains intact, but insulin "antagonism" is present, which may be related to obesity, excess of free fatty acids, synalbumin, inadequate peripheral utilisation of glucose, or secretion of biologically inactive insulin. Hence, higher than normal blood sugar levels may be found in older subjects without tendency to ketosis and in spite of good insulin response to a glycaemic stimulus.

There is plenty of evidence to show the first possibility is unlikely since Wrenshall [15] assayed the insulin content of the pancreases of young and old subjects and found little difference in the total volumes. Andrew [16] and other workers have looked at the islets in experimental animals and in man and have failed to show convincing degenerative changes with age. The second possibility seems unlikely since glucose absorption seems to be little impaired by age.

As yet comparatively few studies have been done comparing glucose levels with insulin levels after a glucose load. Those studies which have been done suggest the defect, if one exists, is within the framework of the third hypothesis. Chouverakis et al. [17] conclude that old people maintain the same blood sugars as young people, but only under the influence of higher circulating insulin levels. Butterfield et al. [18] suggest impairment of the disappearance of insulin from the circulation. Langs et al. [19] suggest that delayed glucose uptake from the plasma is due to decreased tissue sensitivity to insulin and Streeten et al. [20] believe there are increased circulating antagonists and hence higher insulin levels. Crockford et al. [21] found reduced insulin levels in response to intravenous insulin. More recently, Joffe et al. [22] have studied the insulin reserve in the elderly (mean age 82 years) using a combined intravenous tolbutamide and glucagon test $30 \mathrm{~min}$ after oral glucose; blood glucose levels were higher in the elderly group, the plasma insulin levels were lower and the response of the elderly group to acute islet cell stimulation resembled patients with mild "essential" diabetes. Zeytinoglu et al. [23] have also studied the problem in forty subjects, twenty males and twenty females. The age range was lower than our series, being 68-91. Otherwise, the group was similar to ours in that they were selected nondiabetic geriatric ward patients, the majority of whom were active and considered to be "self-care", as indeed were our own. Their methods were similar to our own with the exception that they used a $100 \mathrm{~g}$ loading dose of glucose and prolonged their test to $300 \mathrm{~min}$.

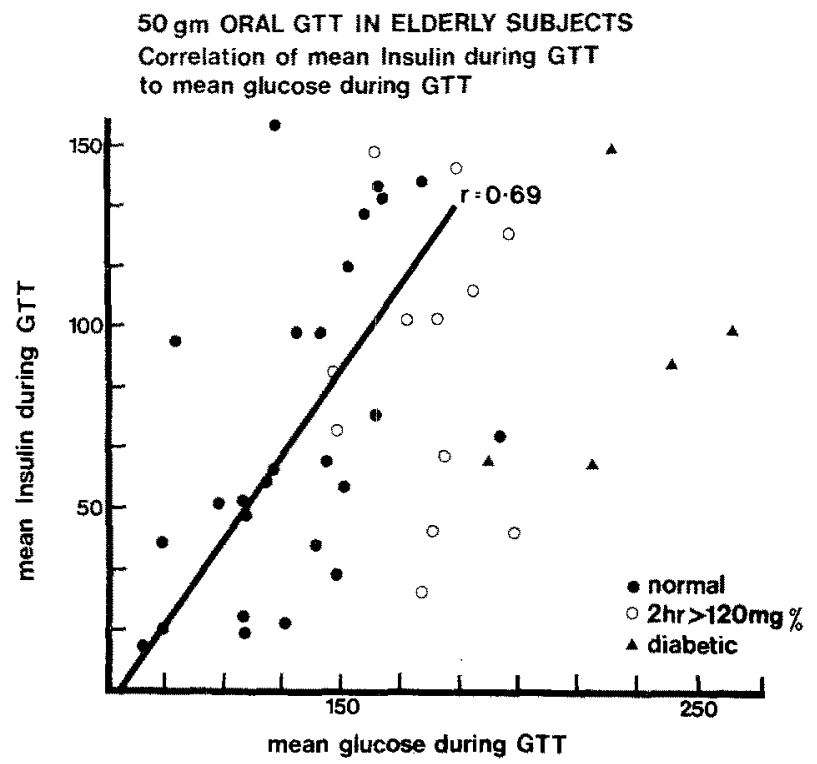

Fig. 1. $50 \mathrm{gm}$ oral G.T.T. in elderly subjects - correlation of mean insulin to mean glucose

Our diabetics show, as do other maturity onset diabetics, an apparent hyperinsulinism. However, if we turn to the comparisons of the areas under each curve, we see that although the area under the insulin curve for the diabotic is larger than the normal, the ratio of glucose to insulin is disturbed. For the normals, the glucose/insulin ratio is $2.02: 1$ and for diabetics $2.4: 1$. In other words, for that degree of glycaemic stimulus, even more insulin is required. Or again, the insulin appears to be ineffective despite the increased secretion and this could be due to some antagonistic effect. This can be illustrated in a different way (Fig. 1). Here the correlation between mean glucose and mean insulin, calculated by the area method, dividing the area value by the time units, is shown for the elderly subjects 
There is a good correlation $r=0.69$ for the normals. This suggests that insulin-glucose are fairly closely inter-related, but the diabetics and the marginal diabetics are shifted to the right, illustrating grossly inadequate insulin secretion compared with glucose load.

Finally, the correlation between the mean insulin and the insulin increment at $30 \mathrm{~min}$ is shown (Fig. 2), If as suggested by Seltzer el al. [24], there was an initial sluggishness of the islets, with a late overswing, then there would be poor correlation between the early rise in insulin and the total insulin seereted. The correlation for the normals is shown $(r=0.739)$. The marginal diabetic group fall very closely around that regression line. Four of the six diabetics are shifted to the right, but they are well within the scatter for the normal group. This suggests that the fault does not lie in a sluggish initial rise in insulin. The insulin is secreted promptly and this is supported by the finding that the 30 min insulin values of the three sub-groups are virtually identical (Table 1).

\section{$50 \mathrm{gm}$ ORAL GTT IN ELDERLY SUBJECTS} Correlation of insulin increment at 30 mins to mean Insulin during GTT

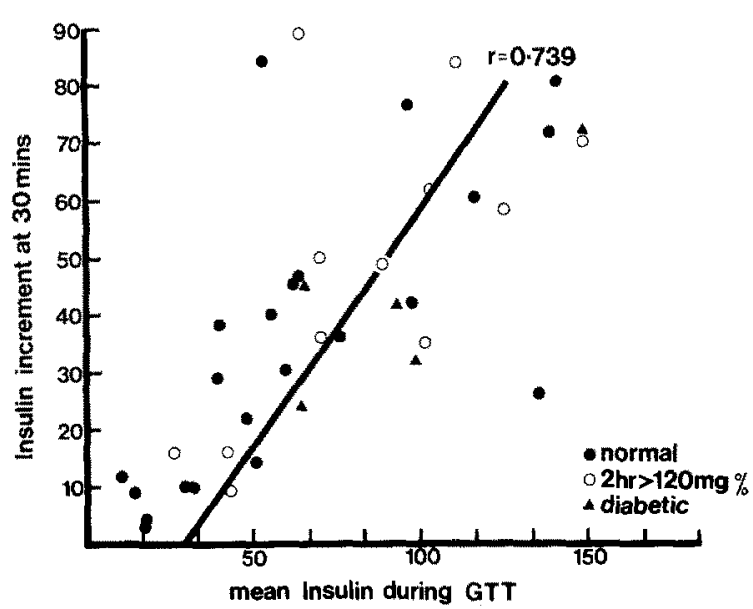

Fig. 2. Correlation of insulin increment at 30 min to mean insulin

It would seem therefore from these results that in spite of a good insulin response to glycaemic stimulus, these very old subjects have higher than normal blood sugar levels. This suggests that the insulin secreted is either less biologically active or its action is ineffective on account of "antagonism" which is unrelated to obesity.

\section{References}

1. Oakley, W.G., Pyke, D.A., Taylor, K.W.: Clinical diabetes and its biochemical basis, p. 183. Oxford; Blackwell 1968

2. Butterfield, W.J.M. : Diabetes survey in Bedford 1962 , Proc. roy. Soc. Med. 57, $196-200$ (1964)
3. U.S. Department of Health, Education and Welfare: Glucose tolerance in adults, U.S. National Center for Health Statistics, Series 11, 2, $(1960-62)$

4. Joslin, E.P., Root, H.F., White, P., Marble, A.: The treatment of diabetes mellitus p. 34. London: $H$. Kimpton 1952

5. Korenchevsky, V.: Physiological and pathological ageing, p. 368. Basel: S. Karger 1962

6. Klotzbucher, E.: Die Alterabhängigkeit des Kohlehydratstoffwechsels. Z. Alternsforsch. 4, 354, (194244)

7. Bogdanovich, R.I.: On carbohydrate metabolism in very old persons. J. Med. Acad. Se. Ukr. S.S.R. 19, $283-1290(1940)$

8. Chesrow, E.J., Blayer, J.M.: The glucose tolerance test in the aged. Geriatrics 9, 276-282 (1954)

9. Keen, H., Rose, G., Pyke, D.A., Boyns, D., Chlouverakis, C., Mistry, S.: Blood sugar and arterial disease. Lancet $\mathbf{1 9 6 5}$ II, $505-508$

10. Hoffman, W.S.: Rapid photoelectric method for determination of glucose in blood and urine. $J$. biol. Chem. 120, $51-55$ (1937)

11. Hales, C.N., Randle, P.J.: Immunoassay of insulin. with insulin antibody precipitate. Biochem. J. 88, $137-146(1963)$

12. Hall, M.R.P., Clarke, E.M., Sanderson, R.L.: The needs of the elderly, Proc. 7 th Int. Cong. Geront., Vienna 1966

13. Briggs, J.D., Buchanan, K.D., Luke, R. G., MoKiddie, M.T.: Role of Insulin in glucose intolerance in uraemia. Lancet $1967 \mathrm{I}, 462-467$

14. Grad, B., Kral, V.A.: The delayed effect of A.C.T.H. administration on the plasma corticoid level of normal elderly persons and patients with chronic brain syndrome. J. Amer. Geriat. Soc. 17, 15-24 (1969)

15. Wrenshall, G.A., Bogoch, A., Ritchie, R.C.: Extractable insulin of pancreas. Diabetes, 1, 87-107 (1952)

16. Andrew, W.: Senile changes in the pancreas. Amer. J. Anat. 74, 97-106 (1964)

17. Chlouverakis, C., Jarrett, R.J., Keen, H.: Glucose tolerance, age and circulating insulin. Lancet $1967 \mathrm{I}$, $806-809$

18. Butterfield, W.J.H., Garratt, C.J., Whichelow, M.J.: Peripheral hormone action: Studies on the clearance and effect of $131-I$ iodoinsulin in the peripheral tissues of normal, acromegalie and diabetic subjects. Clin. Sci. 24, 331-341 (1963)

19. Langs, H.M., Andres, R., Pozefsky, T., Gregerman, R.I.: Responses in serum insulin concentration to the cortisone glucose tolerance test. Diabetes 15, 539 (1966)

20. Streeten, D.H.P., Gerstein, M.M., Marmor, B.M., Doisy, R.J.: Reduced glucose tolerance in elderly human subjects. Diabetes 14, $579 \rightarrow 583(1965)$

21. Crockford, P.M., Harbeck, R.J., Williams, R.H.: Influence of age on intravenous glucose tolerance and serum immunoreactive insulin. Lancet $1966 \mathrm{I}, 465-$ 467

22. Joffe, B., Vinik, A.I., Jackson, W.P.U.: Insulin reserve in elderly subjects. Laneet $1969 \mathrm{I}, 292-293$

23. Zeytinoglu, I.Y., Gherondache, C.N., Pincus, G.: The process of aging; serum glucose and immunoreactive insulin levels during the oral glucose tolerance test. J. Amer. Geriat. Soc. 17, 1-14 (1969)

24. Seltzer, H.S. ,Allen, E.W., Herron, A. L. Jr., Brennon, M. 'T. : Insulin secretion in response to glycemic stimu" lus. J. clin. Invest. 46, 323-335 (1967)

Prof. M. R.P. Hall

Department of Geriatric Medicine

Southampton General Hospital

Tremona Road

Southampton $5094 \mathrm{XY}$

Eingland 